\title{
Protection of the Eye from Ultraviolet Radiation Damage Among Adults in Addis Zemen Town, Northwest Ethiopia
}

This article was published in the following Dove Press journal: Clinical Optometry

\section{Gizachew Tilahun Belete (D) Kalkidan Getahun Tolessa Mohammed Seid Hussen}

University of Gondar, College of Medicine and Health Science, Department of Optometry, Gondar, Ethiopia
Correspondence: Gizachew Tilahun Belete University of Gondar, College of Medicine and Health Science, Department of Optometry, Gondar, Ethiopia Tel +25l (0)9l2684323

Email gizachewtilahun I@gmail.com
Background: Ultraviolet radiation is electromagnetic radiation or light having a wavelength of less than $400 \mathrm{~nm}$ but greater than $100 \mathrm{~nm}$. Ultraviolet radiation, majorly from sunlight, can potentially damage any organ that is exposed to any part of its spectrum. Aside from the skin, the organ most susceptible to sunlight-induced damage is the eye. Ultraviolet radiation is reported to be the cause of multiple ocular problems ranging from benign conditions like pterygium and pinguecula to ocular malignancies such as basal cell carcinoma which finally leads to visual impairment and blindness. Protection practice is mandatory to avoid the burden of diseases caused by ultraviolet exposure and maximizing the protection measures implementation is important. To maximize this, it is essential to know the current practice and the associated factors affecting the usage of protective devices in the study area.

Methods: Community-based cross-sectional study was conducted from April to May 2019 on 453 study participants. The study participants were selected through a systematic random sampling method. Data were collected using a pretested structured questionnaire. The analyzed result was summarized and presented using texts, tables and charts. A Chi-square test was applied to assess the significant association.

Results: A total of 430 study subjects were participated and completed the questionnaire with a response rate of $94.92 \%$. The mean age of the study participants was 35.3 (SD \pm 6.68 ). Two hundred forty-three (56.5\%) study participants were males. About $228(53 \%)$ of participants were married, and $356(82.8 \%)$ were Christian in religion. From the total study participants, $173(40.23 \%)$ had good practice in protecting the eye from ultraviolet radiation damages while the remaining $59.77 \%$ had poor practice. A significant association was found between sex and protection practice of the eye from ultraviolet radiation damages. Conclusion: The majority of the study participants had poor protection practice of the eye from ultraviolet radiation damages. Improving awareness and protection practice are vital to reduce the burden of ocular abnormalities due to excessive exposure to ultraviolet radiation.

Keywords: ultraviolet radiation, protection practice, Addis Zemen Town, Ethiopia

\section{Introduction}

Ultraviolet radiation is an electromagnetic spectrum with a short wavelength between 100 and 400nm. Prolonged exposure to the sun increases exposure to this radiation which can cause chronic skin, ${ }^{1}$ ocular and immune-related health problems. ${ }^{2,3}$

The sensitivity of the eye to ultraviolet radiation (UVR) has been documented in both animal and human studies. ${ }^{4}$ Ultraviolet radiation is reported to be the cause of multiple ocular problems ranging from benign conditions like pterygium and pinguecula to ocular malignancies such as basal cell carcinoma. ${ }^{4-12}$ 
Even though the contribution of UV radiation to the global burden of disease has not yet been quantified, $25-33 \%$ of the global disease burden can be attributed to environmental risk factors. According to estimates by the World Health Organization, Worldwide, 12 to 15 million people become blind from cataracts annually, of which up to $20 \%$ may be caused or enhanced by sun exposure. ${ }^{3}$ To avoid the consequences of ultraviolet radiation on the eye there are several protective measures to be taken. Wearing wide-brimmed hat, ${ }^{13}$ sunglasses, ${ }^{13-15}$ wearing glasses with anti-reflective coatings, ${ }^{16}$ avoiding mid-day sun and provision of shades can reduce the ocular dose of ultraviolet radiation. ${ }^{13}$

Worldwide, some studies suggest that there has been an increase in the awareness of adverse effects of ultraviolet radiation exposure on the $\operatorname{skin}^{1,5,13,17-19}$ and even lesser studies on the eyes, however having the awareness and knowledge does not guarantee the use of the appropriate protective measures. ${ }^{5,6,12,18,20}$

The few studies conducted show that there is poor practice of implementing the protective measures against ultraviolet exposure of the eyes, ${ }^{5,6,21,22}$ and since the usage of protection practice is mandatory to avoid the burden of diseases caused by the ultraviolet exposure, maximizing the protection measures implementation is important. In order to maximize this, it is essential to know the current practice and the associated factors affecting the usage of protective devices. In the study area, there is no evidence suggesting the current practice creating a knowledge gap and affecting which measures to take for the future in reducing the burden of ultraviolet exposure-related ocular morbidities. This study aims to fill the gap and provide baseline data on the current protection practice and associated factors of ultraviolet radiation hazards to the eye.

\section{Methods and Materials}

\section{Study Design, Study Area and Period}

A community-based cross-sectional study was conducted in Addis Zemen town, Northwest Ethiopia, from April to May 2019. Data obtained from Addis Zemen town administration's statistical office indicated that Addis Zemen city is located $\sim 650$ kilometers from the capital city of Ethiopia, Addis Ababa. It is a town in northwest Ethiopia with a latitude and longitude of $12^{\circ} 07^{\prime} \mathrm{N} 37^{\circ}$ $47^{\prime} \mathrm{E}$ and an elevation of about 1975 meters above sea level. The place is classified as humid subtropical bordering with subtropical high lands where ultraviolet radiation from sunlight could have a hazardous effect. According to the 2007 Ethiopian national census, the city has a total population of 37,347 with four Kebeles (the smallest administrative unit) which hosts approximately 14,232 households. There are one governmental hospital, one health center and few private clinics.

\section{Study Population, Sample Size and Sampling Procedure}

The study population was all adults living in Addis Zemen town. The sample size was determined by using the single population proportion formula with the following assumptions. Level of significance $(\alpha)=5 \%$ (with a confidence level of $95 \%)$, marginal error $(\mathrm{w})=4 \%, \mathrm{P}=22 \%(0.22)$ (taken from similar study done in Australia by considering regular and frequent use of sunglass as a good practice in protecting ultraviolet radiation), ${ }^{5} \mathrm{Z}$-value of 1.96 at $95 \%$ for a confidence level. $(\mathrm{n}=$ sample size, $\mathrm{P}=$ proportion, $\mathrm{w}=$ marginal error).

$$
\begin{gathered}
n=\frac{Z^{2} \alpha / 2 p(1-p)}{W^{2}} \\
=\frac{(1.96)^{2}(0.22)(0.78)}{(0.04)^{2}}
\end{gathered}
$$

$=412$

Considering $10 \%$ for non-respondents, the final sample size determined was 453 .

A simple random sampling method was used to select the first household and then systematic random sampling with an interval of $31(\mathrm{k}=31)$ was applied to select the remaining households. A simple random method (lottery) has been employed in a household when there was more than one participant in the selected household. Participants with a serious illness that makes them unable to communicate directly or through the translator to the interviewer were excluded. Individuals who stay indoors or who were not exposed to any other sources of ultraviolet radiation for the last one year were not also included in the study.

\section{Data Collection Tool and Procedure}

The data were collected using a structured and standardized questionnaire. The questionnaire comprised 8 sociodemographic questions, 10 major and 4 elaborative questions regarding the protection practice of the eyes from ultraviolet radiation damages. The questionnaire was first prepared in the English language, then translated to Amharic (local language), and later back-translated to the English language to maintain its consistency. The data were collected by trained optometrists through face to face interviews. 
Protection practice was also assessed by using 14 questions. Each correct response was scored as 1 and each wrong response had a score of 0 . The sum of scores varied from 0 to 14 points. Finally, the overall protection practice of the eyes from ultraviolet radiation damage was categorized as good or poor using the mean score as a cutoff point. Participants who scored the mean and above were considered as doing good practice while any score below the mean was grouped under poor practice.

\section{Data Analysis}

After the data were checked for completeness and cleared, it was coded and entered into Epi-data version 3.1 and analyzed by SPSS version 20 . The descriptive statistics parameters were summarized using measures of central tendency and dispersion. A Chi-square test was applied to identify possible associations of factors for the protection practice of the eye from ultraviolet radiation damages. The analyzed data were organized and presented in a tabular form.

\section{Results}

\section{Socio-Demographic Characteristics of Study Participants}

In this study, a total of 430 study subjects were participated and completed the questionnaire with a response rate of $94.92 \%$. The mean age of the study participants was 35.3 ( $\mathrm{SD} \pm 6.68$ ). Two hundred forty-three $(56.5 \%)$ study participants were males while 228 (53\%) of participants were married and, 356 $(82.8 \%)$ were Christian in religion. Almost half $(48.6 \%)$ of the study participants had completed either primary or secondary school. Regarding the study participants' occupation, 123 $(28.60 \%)$ was employed followed by merchants, $116(27 \%)$ (See Table 1).

\section{Protection Practice of the Eye from Ultraviolet Radiation Damage}

From the total study participants, $173(40.23 \%)$ had good practice in protecting the eye from ultraviolet radiation damages while the remaining $59.77 \%$ had poor practice (See Figure 1).

\section{Wearing Time and Mechanism of Protection of the Eye from Ultraviolet Radiation}

Among ultraviolet protection users, 112 (26.04\%) used either sunglasses or photochromic lenses followed by
Table I Socio-Demographic Characteristics of Study Participants in Addis Zemen Town, Northwest Ethiopia, 2019

\begin{tabular}{|c|c|c|}
\hline Variables & Frequency $(n=430)$ & Percent (\%) \\
\hline \multicolumn{3}{|l|}{ Sex } \\
\hline Male & 243 & 56.51 \\
\hline Female & 187 & 43.49 \\
\hline \multicolumn{3}{|l|}{ Age (Years) } \\
\hline$<25$ & 126 & 29.30 \\
\hline $26-30$ & 98 & 22.79 \\
\hline $31-43$ & 101 & 23.49 \\
\hline$>43$ & 105 & 24.42 \\
\hline \multicolumn{3}{|l|}{ Religion } \\
\hline Christian & 356 & 82.79 \\
\hline Muslim & 74 & 17.21 \\
\hline \multicolumn{3}{|l|}{ Marital status } \\
\hline Single & 161 & 37.44 \\
\hline Married & 228 & 53.03 \\
\hline Divorced & 27 & 6.28 \\
\hline Widowed & 14 & 3.25 \\
\hline \multicolumn{3}{|l|}{ Educational status } \\
\hline No education & 91 & 21.16 \\
\hline Non-formal education & 63 & 14.65 \\
\hline Primary school & 107 & 24.88 \\
\hline Secondary school & 102 & 23.72 \\
\hline College and above & 67 & 15.58 \\
\hline \multicolumn{3}{|l|}{ Occupation } \\
\hline Employed & 123 & 28.60 \\
\hline Merchant & 116 & 26.98 \\
\hline Student & 103 & 23.95 \\
\hline Housewife & 64 & 14.88 \\
\hline Other & 24 & 5.58 \\
\hline \multicolumn{3}{|l|}{ Household income } \\
\hline$<2500$ ETB & 183 & 42.56 \\
\hline$\geq 2500$ ETB & 247 & 57.44 \\
\hline
\end{tabular}

antireflection coated glasses. A significant number of participants, $123(28.6 \%)$ did not use any type of protection.

More than $70 \%$ of protection users wore their protection device between $10 \mathrm{AM}$ and $2 \mathrm{PM}$ when ultraviolet radiation reaches its peak. The majority of study participants used protective device to protect ultraviolet radiation from sunlight (see Table 2).

\section{Association Between Protection Practice and Socio-Demographic Characteristics}

Among participants who had poor protective practice, males account for $35 \%$. Fifty percent of participants 


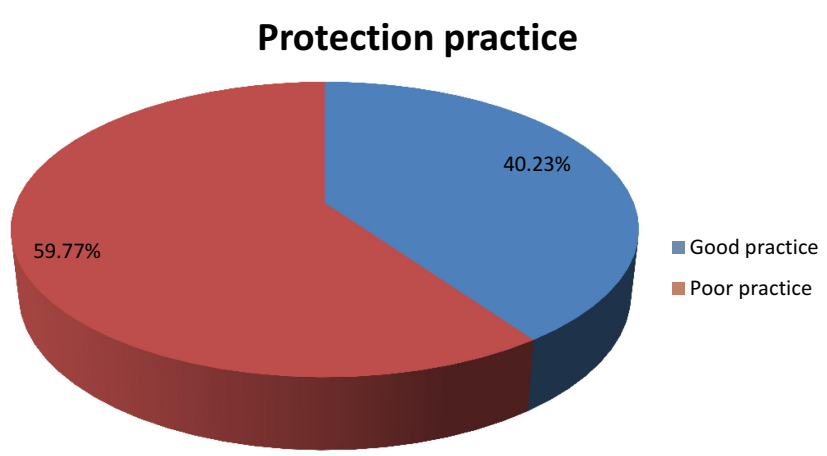

Figure I Protection practice of the eye from ultraviolet radiation among adults in Addis Zemen town, Northwest Ethiopia, 2019.

with poor protective practice are Christians in their religion.

By applying the chi-square test, a significant association has been found between sex and protection practice of the eye from ultraviolet radiation damages $(P=0.03)$ but no other significant association was obtained between socio-demographic variables and

Table 2 Wearing Time, Protective Device and Sources of Ultraviolet Radiation Among Adults in Addis Zemen Town, Northwest Ethiopia, 2019

\begin{tabular}{|l|l|l|}
\hline Variables & Frequency & Percent (\%) \\
\hline $\begin{array}{l}\text { Protection materials/means } \\
\text { (n=430) }\end{array}$ & & \\
Sunglass/photochromic lens & 112 & 26.04 \\
Combined ARC and tint glasses & 57 & 13.25 \\
Occupational safety glass & 38 & 8.83 \\
Brimmed hat & 35 & 8.13 \\
Clothes & 21 & 4.88 \\
Umbrella & 29 & 6.74 \\
No protection & 123 & 28.60 \\
Others & 15 & 3.49 \\
\hline Protection wearing time (n=307) & & \\
I2 AM to I0 AM & 35 & 11.40 \\
I0 AM to 2 PM & 221 & 71.97 \\
2 PM to I2 AM & 51 & 16.61 \\
\hline Protection of eye from (UVR & & \\
sources) (n=307) & & \\
Sunlight & 170 & 45.95 \\
Welding arc & 38 & 10.27 \\
Visual display units emissions & 52 & 14.05 \\
Reflection from snow/ocean/sea & 18 & 4.86 \\
Reflection from buildings/roads & 21 & 5.68 \\
Others & 7 & 1.89 \\
\hline
\end{tabular}

protection practice of the eye from UVR damages (See Table 3).

\section{Discussion}

In this study, the proportion of good practice to protect the eye from ultraviolet radiation damage was $40.23 \%(95 \%$ CI: 36.62-48.91\%) which was in line with studies done in Canada, Brazil and Malta. ${ }^{23-26}$ This level of protection practice is categorized as low which needs prevention and protection campaigns to reduce the damages of ultraviolet radiation.

The proportion of protective practice in this study is lower than studies done in different states of America $(69 \%$ and $80 \%)$ and Australia (71\% and 61\%). ${ }^{6,27-29}$

Table 3 Distribution of Protection Practice Among SocioDemographic Characteristics in Addis Zemen, Northwest Ethiopia, 2019

\begin{tabular}{|c|c|c|c|}
\hline \multirow[t]{2}{*}{ Variables } & \multicolumn{3}{|c|}{ Protection Practice } \\
\hline & Good & Poor & p-value \\
\hline \multicolumn{4}{|l|}{ Sex } \\
\hline Male & 94 & 149 & 0.03 \\
\hline Female & 79 & 108 & \\
\hline \multicolumn{4}{|l|}{ Age } \\
\hline$<25$ & 50 & 76 & 0.52 \\
\hline $26-30$ & 39 & 59 & \\
\hline $31-43$ & 41 & 60 & \\
\hline$>43$ & 43 & 62 & \\
\hline \multicolumn{4}{|l|}{ Religion } \\
\hline Christian & 143 & 213 & 0.82 \\
\hline Muslim & 30 & 44 & \\
\hline \multicolumn{4}{|l|}{ Educational status } \\
\hline No education & 37 & 54 & 2.75 \\
\hline Non formal education & 25 & 38 & \\
\hline Primary school & 43 & 64 & \\
\hline Secondary school & 41 & 61 & \\
\hline College and above & 27 & 40 & \\
\hline \multicolumn{4}{|l|}{ Occupation } \\
\hline Employed & 49 & 74 & 0.16 \\
\hline Merchant & 47 & 69 & \\
\hline Student & 41 & 62 & \\
\hline Housewife & 26 & 38 & \\
\hline Others & 10 & 14 & \\
\hline \multicolumn{4}{|l|}{ Household income (ETB) } \\
\hline$<2500$ & 74 & 109 & 0.21 \\
\hline$\geq 2500$ & 99 & 148 & \\
\hline
\end{tabular}

Abbreviations: ETB, Ethiopian Birr; household income, average monthly household or family income. 
This difference may be due to variations in the nature of the profession, time spent recreation, geographical location and level of knowledge. Study subjects (over 80\%) in the USA who use ultraviolet protective devices were lifeguards in their profession. Because of the nature of the profession, these subjects are forced to use the protective device but none of the participants in this study were lifeguards. The other study in Galveston, USA (69\% use protective device) includes participants who spent the majority of their at the beach area. The study subjects in western Sydney (Australia-61\% use protective devices) were outdoor workers. Both in the American and Australian studies, the proportion of awareness and knowledge about the protection of UVR is high which leads to a better use of the protective device to avoid its damage. In the study area, there are only a few awareness campaigns and low eye care service utilization. Additionally, the study settings both in Australia and America are at higher risk of UVR exposure which enforces individuals to use the protective device.

However, the protective practice of the eye from ultraviolet radiation damages found in this study was higher than the studies done in South Australia, Brazil, South Africa and California (America). ${ }^{5,30-32}$ The difference is likely due to the differences in the study population characteristics. The study subjects in South Australia (1-18 years) and Brazil (university students with a mean age of 22 years) were younger than this study (mean age 35.3 with a range of $18-85$ years). There were also differences in sampling technique and sample size (large sample size in the case of South African study). Another possible explanation for this difference could be the criteria or base of classification as some of the studies used median and other methods to classify protective practice than the mean value. Likewise, the possible source of differences includes; study design and settings, socio-economic variations, level of awareness and health care seeking and utilization.

Sex was found to have a significant association with the protective practice of the eye from ultraviolet radiation damages $(P=0.03)$. This finding was evidenced and supported by other studies. ${ }^{27,31}$ This could be explained in either way as most males are outdoor workers where they are at a state of exposure to ultraviolet radiation. This frequent exposure may enforce subjects to use some type of protective device to prevent the damaging effects of ultraviolet radiation on the eyes. On the other side, females are more conscious of their beauty and usually protecting their bodies from sunlight exposure by sunscreens and umbrellas.

As a limitation of the study, there were limited works of literature done in the area which makes the comparison a bit difficult. Most of the published researches reviewed in this study were more on skin protection. Additionally, works of literature did not label the habit of protection practice but focused on the type of protection methods and devices which make direct comparison and explanation were not adequate.

\section{Conclusion}

The majority of the study participants had poor protection practice of the eye from ultraviolet radiation damages. A significant association was found between sex and protection practice of the eye from ultraviolet radiation damages. Improving awareness and protection practice are vital to reduce the burden of ocular abnormalities due to excessive exposure to ultraviolet radiation.

\section{Data Sharing Statement}

The data sets generated and analyzed for the current study are available from the corresponding author and accessed upon reasonable request.

\section{Ethical Approval}

Ethical clearance and approval were obtained from the Ethical Review Committee, University of Gondar. Both the study and verbal informed consent were also approved by the Ethical Review Committee, University of Gondar. The study was conducted in accordance with the Declaration of Helsinki. The objective of the study was clearly described for each participant. Then, oral informed consent was received from each study participant. The survey participants were granted the full right to cease or refuse to take part. Confidentiality was assured through keeping records and omitting any participants' identifiers.

\section{Author Contributions}

All authors contributed to data analysis, drafting or revising the article, have agreed on the journal to which the article will be submitted, gave final approval of the version to be published, and agree to be accountable for all aspects of the work.

\section{Disclosure}

The authors declare that we have no conflicts of interest regarding this work or the publication of this article. 


\section{References}

1. Grandahl K, Ibler KS, Laier GH, Mortensen OS. Skin cancer risk perception and sun protection behavior at work, at leisure, and on sun holidays: a survey for Danish outdoor and indoor workers. Environ Health Prev Med. 2018;23(1):47. doi:10.1186/s12199-018-0736-x

2. Robyn L, Tony M, Wayne S, Bruce A. Solar Ultraviolet Radiation: Global Burden of Disease from Solar Ultraviolet Radiation. Geneva: World Health Organization; 2006.

3. WHO. Intersun - The Global UV Project: A Guide and Compendium. Geneva: World Health Organization; 2003.

4. Rosenthal FS, Safran M, Taylor H. The ocular dose of ultra violet radiation from sunlight exposure. Photochem Photobiol. 1985;42 (2):163-171. doi:10.1111/j.1751-1097.1985.tb01555.x

5. Pakrou N, Casson R, Fung S, Ferdowsi N, Lee G, Selva D. South Australian adolescent ophthalmic sun protective behaviours. Eye. 2006;22:808-814. doi:10.1038/sj.eye.6702619

6. Lee GA, Hirst LW, Sheehan M. Knowledge of sunlight effects on the eyes and protective behaviors in adolescents. Ophthalmic Epidemiol. 1999;6(3):171-180. doi:10.1076/opep.6.3.171.1501

7. Rosenthal Aeb FS, Taylor H. The effect of prescription eyewear on ocular exposure to ultraviolet radiation. AJPH. 1986;76:10.

8. Informal Consultation on the Effects of Solar UVRotE, Blindness WHOPftPo, World Health Organization. Office of G, Integrated Environmental H. The Effects of Solar UV Radiation on the Eye: Report of an Informal Consultation, Geneva, 30 August 3 September 1993. Geneva: World Health Organization; 1994.

9. Lindgren G, Diffey BL, Larko O. Basal cell carcinoma of the eyelids and solar ultraviolet radiation exposure. BRJ Ophthalmol. 1998;82 (12):1412-1415. doi:10.1136/bjo.82.12.1412

10. Sliney DH. Ocular exposure to environmental light and ultraviolet the impact of lid opening and sky conditions. Dev Ophthalmol. 1997;27:63-75.

11. Young RW. The family of sunlight related eye disease. Optom Vis Sci. 1994;71(2):125-144. doi:10.1097/00006324-199402000-00013

12. Lee Graham A, Hirst Lawrence W, Sheehan M. Knowledge of sunlight effects on the eyes and protective behaviors in the general community. Ophthalmic Epidemiol. 1994;1(2):67-84. doi:10.3109/ 09286589409052363

13. Peter H. Protection against solar ultraviolet radiation. Mutat Res. 1998;15-22.

14. Frank S, Bakalian AE, Lou CQ, Taylor HR. The effect of sunglasses on ocular exposure to ultraviolet radiation. Am J Public Health. 1988;78(1):72-74. doi:10.2105/AJPH.78.1.72

15. Sliney DH. Photoprotection of the eye - UV radiation and sunglasses. J Photochem Photobiol B. 2001;64(2-3):166-175. doi:10.1016/ S1011-1344(01)00229-9

16. Citek K. Anti-reflective coatings reflect ultraviolet radiation. Optometry. 2008;79(3):143-148. doi:10.1016/j.optm.2007.08.019

17. Diffey BL. Sunscreens as a preventative measure in melanoma: an evidence-based approach or the precautionary principle? $\mathrm{Br}$ J Dermatol. 2009;161:25-27. doi:10.1111/j.1365-2133.2009.09445.x
18. Parkin DM, Mesher D, Sasieni P. Cancers attributable to solar (ultraviolet) radiation exposure in the UK in 2010. Br J Cancer. 2011;105 (S2):S66-S9. doi:10.1038/bjc.2011.486

19. Cook BE, Bartley GB. Treatment options and future prospects for the management of eyelid malignancies. Ophthalmology. 2001;108 (11):11. doi:10.1016/S0161-6420(01)00796-5

20. Thomas-Gavelan E, Sáenz-Anduaga E, Ramos W, Sánchez-Saldaña L, Sialer M. Knowledge, attitudes and practices about sun exposure and photoprotection in outpatients attending dermatology clinics at four hospitals in Lima, Peru. An Bras Dermatol. 2011;86 (6):1122-1128. doi:10.1590/S0365-05962011000600009

21. Wright CY, Reeder AI, Albers PN. Knowledge and practice of sun protection in schools in South Africa where no national sun protection programme exists. Health Educ Res. 2016;31(2):247-259. doi:10.1093/her/cyw005

22. Janjani H, Nedjat S. Sun exposure and health safety practices of high school students in an urban population of Iran. BMC Public Health. 2019;19(1):19. doi:10.1186/s12889-019-8100-7

23. Campbell HS, Birdsell JM. Knowledge, beliefs, and sun protection behaviors of Alberta adults. Prev Med. 1994;23(2):160-166. doi:10.1006/pmed.1994.1022

24. Dallazem LND, Benvegnú AM, Stramari JM, Beber AAC, Chemello RML, Beck M. Knowledge and habits of sun exposure in university students: a cross-sectional study in Southern Brazil. An Bras Dermatol. 2019;94(2):172-181.

25. Benvenuto-Andrade C, Zen B, Fonseca G, De Villa D, Cestari T. Sun exposure and sun protection habits among high-school adolescents in Porto Alegre, Brazil. Photochem Photobiol. 2005;81(3):630. doi:10.1562/2005-01-25-RA-428.1

26. Scerri L, Aquilina S, Gauci AA, Dalmas M. Sun awareness and sun protection practices in Malta. J Eur Acad Dermatol Venereol. 2002;16(1):47-52. doi:10.1046/j.1468-3083.2002.00376.x

27. Houghtaling PM, Foster T, Heiner DJ, Uchida T, Wagner JR. Eyelid protection from ultraviolet radiation injury at the beach. HPC Suppl Focus Sun Care. 2010;3:12.

28. Cioffi J, Wilkes L, O’Brien J. Outdoor workers and sun protection: knowledge and behaviour. Constr Econ Build. 2002;2(2):10-14. doi:10.5130/AJCEB.v2i2.2896

29. Hall DM, McCarty F, Elliott T, Glanz K. Lifeguards' sun protection habits and sunburns: association with sun-safe environments and skin cancer prevention program participation. Arch Dermatol. 2009;145 (2):139-144. doi:10.1001/archdermatol.2008.553

30. Castilho IG, Sousa M, Leite R. Photoexposure and risk factors for skin cancer: an evaluation of behaviors and knowledge among university students. An Bras Dermatol. 2010;85(2):173-178. doi:10.1590/S0365-05962010000200007

31. Oduntan O, Carelson A, Clarke-Farr P, Hansraj R. South African university student knowledge of eye protection against sunlight. African Vis Eye Health. 2009;68(1):25-31. doi:10.4102/aveh. v68i1.149

32. Salas R, Mayer JA, Hoerster KD. Sun-protective behaviors of California farmworkers. J Occup Environ Med. 2005;47 (12):1244-1249. doi:10.1097/01.jom.0000177080.58808.3b
Clinical Optometry

\section{Publish your work in this journal}

Clinical Optometry is an international, peer-reviewed, open access journal publishing original research, basic science, clinical and epidemiological studies, reviews and evaluations on clinical optometry. All aspects of patient care are addressed within the journal as well as the practice of optometry including economic and business analyses. Basic and clinical research papers are published that cover

Submit your manuscript here: https://www.dovepress.com/clinical-optometry-journal all aspects of optics, refraction and its application to the theory and practice of optometry. The manuscript management system is completely online and includes a very quick and fair peer-review system, which is all easy to use. Visit http://www.dovepress.com/ testimonials.php to read real quotes from published authors. 